\title{
Left atrial appendage device closure as non- pharmacological prevention of thromboembolism in atrial fibrillation
}

\author{
An article from the series "Atrial fibrillation - update 2014» \\ Bernhard Meier \\ Cardiology, Bern University Hospital, Bern, Switzerland
}

\section{Summary}

The fact that non-valvular (non-rheumatic) atrial fibrillation creates detectable thrombi in $17 \%$ of patients without oral anticoagulation and that $16 \%$ of the $17 \%$ (over $90 \%$ relatively) reside in the left atrial appendage (LAA), suggest that patients without an LAA or with an occluded LAA do not need oral anticoagulation. This has already led to surgical LAA exclusion for decades and to catheter-based LAA occlusion for the past 13 years.

Currently 5 different technical approaches are approved in European countries, but only 2 are widely used, the Amplatzer and the Watchman devices. With the latter, randomised data showed superiority in terms of embolism protection, bleeding, and survival compared to vitamin $\mathrm{K}$ antagonists (VKA) after 4 years in a randomised trial. The clinical results in thousands of patients with Watchman and Amplatzer occluders suggest, moreover, that they are at least competitive with non-VKA oral anticoagulants. Non-pharmacological prevention of thromboembolism with device implantation or, in case of another indication for heart surgery during that intervention, may be discussed with every patient with atrial fibrillation as an alternative to oral anticoagulation. closure

Key words: atrial fibrillation; left atrial appendage

\section{Introduction}

It is known from autopsy, cardiac surgery, and transoesophageal echocardiography (TOE) that $17 \%$ of patients with non-valvular (basically non-rheumatic) atrial fibrillation (AF) have clots in the left atrium (LA). Over $90 \%$ of these clots (16\%

Funding / potential competing interests: Speaker honoraria and research grants to the institution of St. Jude Medical. No other potential conflict of interest relevant to this article was reported. of $17 \%$ ) reside in the left atrial appendage (LAA) [1]. Hence, the presence of $1 \%$ of blood clots in patients with no LAA or an occluded LAA provides a risk much too small to warrant chronic oral anticoagulation either with vitamin $\mathrm{K}$ antagonists (VKA) or non-VKA oral anti- coagulants (NOAC). The bleeding risk more than outweighs the potential benefit.

$\mathrm{AF}$ is the most common clinically significant rhythm disorder with an increasing prevalence parallel to the increasing average age of our population. The decision of whether to treat a given patient with VKA, NOAC, or LAA occlusion has to be taken almost daily by cardiologists, internists, and other physicians.

\section{Techniques of left atrial appendage occlusion}

Excision or ligation of the LAA has been part of some surgical procedures for decades [2, 3]. However, these interventions were mostly combined with mitral valve replacement using metallic implants so that the patients needed to stay under oral anticoagulation regardless. No thorough appreciation of the value of LAA exclusion was therefore performed or even possible.

The electrophysiologist Michael Lesh developed a plug device that could be implanted percutaneously, intrigued by the fact that the LAA was easily accessible with catheters used for AF ablation in the LA. He attended the first implantation of his Percutaneous Left Atrial Appendage Transcatheter Occluder (PLAATO, abandoned, Medtronic, Mansfield, MA, USA) on August 30, 2001, by Horst Sievert in Frankfurt, Germany [4]. The results of patients treated with this device were superior to what could be expected with VKA $[5,6]$. The procedure itself, however, was rather intricate, partly due to bulky catheters.

On June 15, 2002, we introduced a more simple technique applicable in a conscious patient under local anaesthesia and without echocardiographic guidance. This technique used various Amplatzer devices (St. Jude, Plymouth, MS, USA) that were market lead-

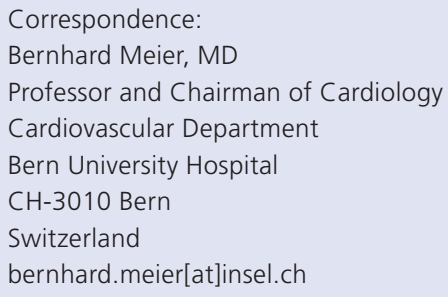


ers in the closure of atrial septal defects (ASD) and patent foramen ovale (PFO) [7]. Figure 1 shows the 1-year follow-up echocardiogram of the world's first patient.

Later the same year, the Watchman device (Boston Scientific, Marlborough, MA, USA) was introduced into clinical medicine (first case on August 12, 2002, performed by Peter Sick) [8]. This device and the Amplatzer devices, in particular the Amplatzer Cardiac Plug (ACP), a modification of the original Amplatzer devices introduced in 2008, currently dominate the market $[9,10]$. The LAA Transcatheter Patch (Custom Medical Devices, Athens, Greece) and the WaveCrest device (Johnson and Johnson, Diamond Bar, CA, USA), the two other devices that are clinically used in Europe, are depicted in figure 2. On rare occasions a hybrid procedure using a left atrial approach combined with a pericardial approach is used [11-13]. This technique is more in competition with mini-invasive surgery [14] than with interventional cardiology.

\section{Percutaneous technique for left atrial appendage occlusion}

While most centres prefer general anaesthesia with endotracheal intubation and TOE guidance, simplifications have been suggested [15]. TOE guidance is possible with deep sedation but bronchial aspiration has to be watched out for (table 1). Intracardiac echocardiography (ICE) has also been recommended [16]. Our group has had good experience with the most frugal of all approaches [10].

\section{Figure 1}

Trans-oesophageal echocardiography of the world's first patient with a left atrial appendage occlusion under non-sedated local anaesthesia and without echocardiographic guidance. The patient was a 63-yearold butcher with atrial fibrillation. He could not take oral anticoagulants for professional reasons. The procedure was performed on June 15, 2002, using an Amplatzer $30 \mathrm{~mm}$ Atrial Septal Occluder and the patient has had no further need for anticoagulation in a clinically uneventful course for over 12 years.

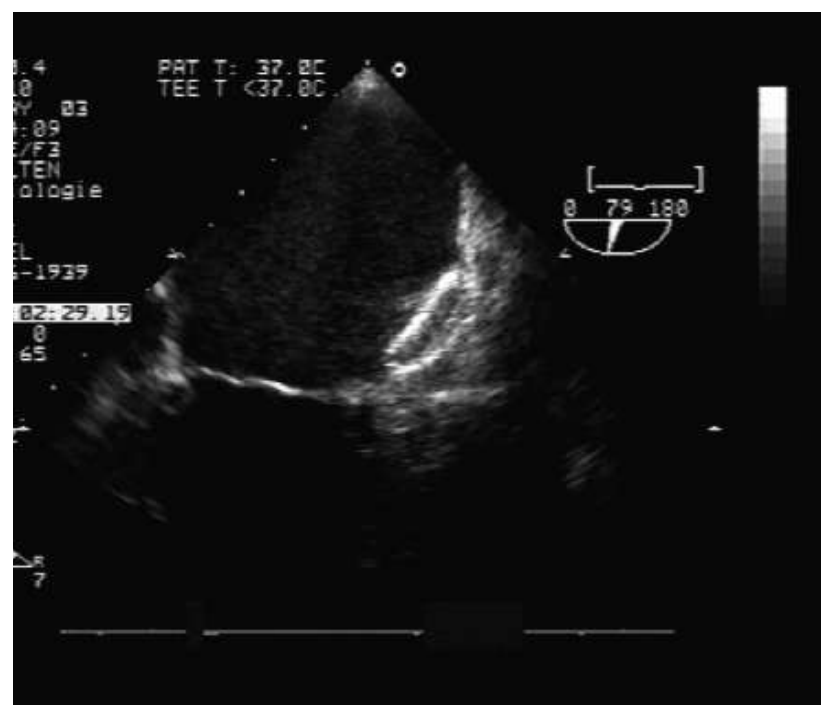

Table 1

Advantages and disadvantages of echocardiographic guidance (trans-oesophageal or intracardiac) for left atrial appendage closure.

Advantages
Less misplacement or sub-optimal placement of device
Less misplacement of additional shunts
Immediate information about result
Less (no) contrast medium injection
Less (no) X-ray exposure
Disadvantages
Need for general anaesthesia or intubation
or else: tube uncomfortable in supine position and risk
of bronchial aspiration
Cost and complications of intracardiac echocardiography
( 2 nd venous access)
Distraction from what is essential in fluoroscopy
Much longer procedure (clots in sheath!)

Most patients undergo a TOE before the procedure to rule out mobile clots in the LAA. It is possible to perform the procedure without prior TOE but this requires a contrast medium injection into the LA at a distance of the LAA to assess for thrombus [17]. While most operators prefer a trans-septal puncture through the septum primum low and posterior in the fossa ovalis, a PFO and, even better, an ASD when present can be used for LA access in most cases. The LAA occlusion can be combined with a variety of other interventions, most commonly coronary angiography, yielding an associated procedure in 41\%, 2 associated procedures in $32 \%, 3$ in $6 \%$, and 4 or more in $1 \%$ at our centre (fig. 3 ). We finish the LAA occlusion with closing a pre-existing atrial septal passage using the same delivery sheath for a second Amplatzer (ASD or PFO) occluder.

A specifically shaped sheath $(13$ French $=4.3 \mathrm{~mm}$ inner and $5.5 \mathrm{~mm}$ outer diameter) is gently introduced into the left atrial appendage and the device is implanted through it. This is performed under heparin (e.g., 5000 units before beginning the procedure) and antibiotic protection (e.g., $1 \mathrm{~g}$ of cephalosporin before the procedure and at least once after the procedure). Stable position of the device and absence of pericardial effusion is usually confirmed by transthoracic echocardiography a few hours later (after mobilisation) and the patient is often discharged the same day. The latest moment of device embolisation appears to be the mobilisation of the patient leading to markedly altered position of the heart. Either oral anticoagulation for a few weeks followed by acetylsalicylic acid (ASA) or, at our centre, clopidogrel for 1 month and ASA for 5 months with or without loading doses are used after discharge. We recommend a TOE at 3 to 6 months to assure proper closure of the LAA and absence of mobile thrombi or of thrombi protruding into the LA. 
Complications of left atrial appendage occlusion

Device embolisation and cardiac perforation with pericardial bleeding are the most feared complications and occur in about 1 to $3 \%$ each. They appear to be deviceindependent and to occur less frequently with more experienced operators. However, the technique is intricate and the learning curve is rather flat. Late device embolisations that have been reported were probably misinterpreted early device embolisations that were clinically silent (as practically all device embolisations are) and were detected only late. Late pericardial effusions, however, do occur, probably more due to pericardial reactions than to late perforations. Nonetheless, late erosion for instance of a pulmonary artery by the retainer hook of an LAA occluder has been reported [18]. Late mobile thrombi on the device detected either by routine TOE follow-up or after a clinical event occur in 3 to $5 \%$. They may need a period of VKA or NOAC if feasible for the patients. Thrombectomy, perhaps with surgical explantation of the device, is an alternative but has rarely been reported.

\section{Figure 2}

Left atrial appendage occluders used in Europe with their year of introduction. The Amplatzer devices are the most commonly used ones followed by the Watchman devices.

\section{Figure 3}

Procedures

associated to left atrial appendage occlusion at our institution in

413 cases.

$\mathrm{AF}=$ atrial

fibrillation; $A S D=$ atrial septal defect; $\mathrm{PCI}=$ percutaneous coronary intervention; $\mathrm{PFO}=$ patent foramen ovale; RF

$=$ radio frequency; $\mathrm{TAVI}=$ transcatheter aortic valve implantation.
2001

PLAATO

(abandoned)

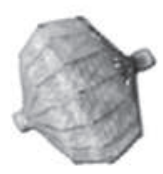

2008

LAA Transcatheter Patch

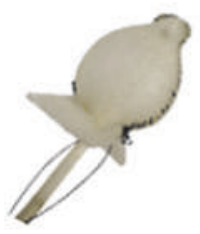

2002

Amplatzer

ASD/PFO/VSD

Occluders

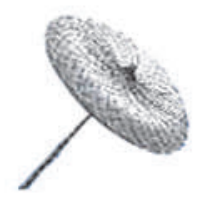

2008

Amplatzer Cardiac Plug Amulet

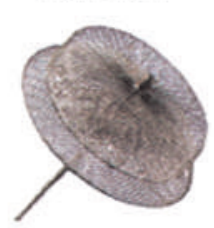

2002

Watchman

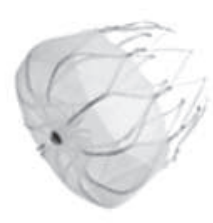

2011

Wavecrest

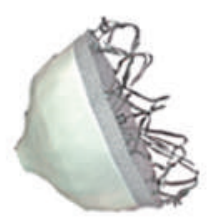

Coronary angiography $67 \%$

PFO closure

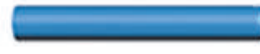

$19 \%$

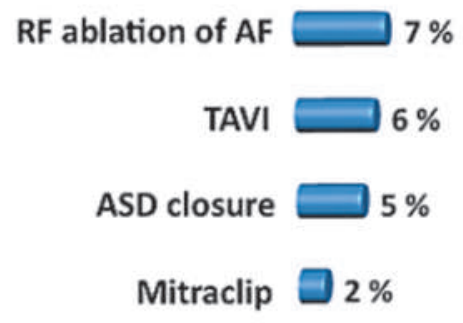

Other procedure $1 \%$ 


\section{Clinical results of left atrial appendage occlusion}

The results of 2 randomised trials with the Watchman device (PROTECT AF, and PREVAIL) [15] and registry publications of thousands of patients treated with Watchman or Amplatzer devices [19-21] attest reasonable safety and surprising efficacy. In particular, the Watchman device proved to reduce mortality over 4 years when compared to Warfarin treatment [20]. A large registry using the Amplatzer device with over 1000 patients showed a mortality curve congruent with that of the PROTECT AF trial [21]. This suggests that both currently leading techniques may be not only superior to VKA but are probably also competitive with NOAC. A respective randomised trial with the Amplatzer device is ongoing.

A cost analysis projected that about 50000 US dollars have to be invested for 1 quality-adjusted year of life with LAA closure compared to VKA while this costs 90000 US dollars with dabigatran, the hitherto most widely used NOAC [22].

\section{Conclusion}

Clinical results with LAA occlusion confirm the theory that eliminating the LAA as a possible source of systemic emboli in AF provides at least as good a protection against systemic emboli as oral anticoagulation with VKA and probably also with NOAC and yields a net benefit because the constant bleeding risk (growing with age) with any type of oral anticoagulation is virtually eliminated. Hence, this option may be discussed with every patient with atrial fibrillation irrespective of whether or not anti-thrombotic treatment has already been started. This has yet to be reflected in guidelines where LAA closure is at best mentioned as an alternative for oral anticoagulation in patients with contraindications to it or unwilling to take it. Moreover, as both methods fail to provide complete prevention against systemic embolism, a combination of them can be considered.

\section{References}

1 Blackshear J, Odell J. Appendage obliteration to reduce stroke in cardiac surgical patients with atrial fibrillation. Ann Thorac Surg. 1996; 61:755-9.

2 Madden J. Resection of the left auricular appendix; a prophylaxis for recurrent arterial emboli J Am Med Assoc. 1949;140:769-72.

3 Bonow R, Carabello B, Chatterjee K, de Leon AJ, Faxon D, Freed M, et al. ACC/AHA 2006 guidelines for the management of patients with valvular heart disease: a report of the American College of Cardiology/ American Heart Association Task Force on Practice Guidelines (writing Committee to Revise the 1998 guidelines for the management of patients with valvular heart disease) developed in collaboration with the Society of Cardiovascular Anesthesiologists endorsed by the Society for Cardiovascular Angiography and Interventions and the Society of Thoracic Surgeons. J Am Coll Cardiol. 2006;48:e1-e148.
4 Sievert H, Lesh M, Trepels T, Omran H, Bartorelli A, Della Bella P, et al. Percutaneous left atrial appendage transcatheter occlusion to prevent stroke in high-risk patients with atrial fibrillation: early clinical experience. Circulation. 2002;105:1887-9.

5 Ostermayer S, Reisman M, Kramer P, Matthews R, Gray W, Block P, et al. Percutaneous left atrial appendage transcatheter occlusion (PLAATO system) to prevent stroke in high-risk patients with non-rheumatic atrial fibrillation: results from the international multi-center feasibility trials. J Am Coll Cardiol. 2005;46:9-14.

6 Bayard Y, Omran H, Neuzil P, Thuesen L, Pichler M, Rowland E, et al. PLAATO (Percutaneous Left Atrial Appendage Transcatheter Occlusion) for prevention of cardioembolic stroke in non-anticoagulation eligible atrial fibrillation patients: results from the European PLAATO study. EuroIntervention. 2010;6:220-6.

7 Meier B, Palacios I, Windecker S, Rotter M, Cao Q, Keane D, et al. Transcatheter left atrial appendage occlusion with Amplatzer devices to obviate anticoagulation in patients with atrial fibrillation. Catheter Cardiovasc Interv. 2003;60:417-22.

8 Sick P, Schuler G, Hauptmann K, Grube E, Yakubov S, Turi Z, et al. Initial worldwide experience with the Watchman left atrial appendage system for stroke prevention in atrial fibrillation. J Am Coll Cardiol. 2007;49:1490-5.

9 Freixa X, Chan JL, Tzikas A, Garceau P, Basmadjian A, Ibrahim R. The Amplatzer Cardiac Plug 2 for left atrial appendage occlusion: novel features and first-in-man experience. EuroIntervention. 2013;8:1094-8.

10 Nietlispach F, Gloekler S, Krause R, Shakir S, Schmid M, Khattab AA, et al. Amplatzer left atrial appendage occlusion: single center 10-year experience. Catheter Cardiovasc Interv. 2013;82:283-9.

11 Lee R, Bartus K, Yakubov S. Catheter-based left atrial appendage (LAA) ligation for the prevention of embolic events arising from the LAA: initial experience in a canine model. Circ Cardiovasc Interv. 2010;3: 224-9.

12 Bartus K, Bednarek J, Myc J, Kapelak B, Sadowski J, Lelakowski J, et al. Feasibility of closed-chest ligation of the left atrial appendage in humans. Heart Rhythm. 2011;8:188-93.

13 Shetty R, Leitner J, Zhang M. Percutaneous catheter-based left atrial appendage ligation and management of periprocedural left atrial appendage perforation with the LARIAT suture delivery system. J Invasive Cardiol. 2012;24:E289-93.

14 Friedman PA, Asirvatham SJ, Dalegrave C, Kinoshita M, Danielsen AJ, Johnson SB, et al. Percutaneous epicardial left atrial appendage closure: preliminary results of an electrogram guided approach. J Cardiovasc Electrophysiol. 2009;20:908-15.

15 Meier B, Blaauw Y, Khattab A, Lewalter T, Sievert H, Tondo C, et al. Catheter Based Left Atrial Appendage Occlusion, Scientific document supported by the European Association of Percutaneous Coronary Interventions (EAPCI) and the European Heart Rhythm Association (EHRA) EuroInterv. 2014; in print.

16 Santoro G, Meucci F, Stolcova M, Rezzaghi M, Mori F, Balmieri C, et al. Percutaneous left atrial appendage occlusion with patients with nonvalvular atial fibrillation: implantation and op to four-years follow-up of the Amplatzer cardiac Plug. EuroInterv. 2014;in print.

17 Nietlispach F, Krause R, Khattab A, Gloekler S, Schmid M, Wenaweser $\mathrm{P}$, et al. Ad hoc percutaneous left atrial appendage closure. J Invasive Cardiol. 2013;25:683-6.

18 Hannazawa K, Brunelli M, Saenger J, Grosse A, Santi R, Lauer B, et al. Clouse proximity between pulmonary artery and left atrial appendage leading to perforation of the artery tamponade and death after appendage closure you using cardiac plug device. Interv J Cardiol. 2014;in print.

19 Park J, Bethencourt A, Sievert H, Santoro G, Meier B, Walsh K, et al. Leithauser B. Left atrial appendage closure with Amplatzer Cardiac Plug in atrial fibrillation: initial European experience. Catheter Cardiovasc Interv. 2011;77:700-6.

20 Reddy V. Watchman LAA closure device reduces the risk of ischemic stroke in patients with AF entirely without anticoagulation. The ASAPlavix (ASAP) Registry. Presentation of Transcatheter Therapeutics (TCT), Miami, Florida, USA. November 2012.

21 Tzikas A, Shakir S, Sievert H, Omran H, Berti S, Santoro G, et al. Left atrial appendage occlusion for stroke prevention in atrial fibrillation: multicenter experience with the Amplatzer Cardiac Plug. EuroInterv. 2014 ;in print.

22 Singh SM, Micieli A, Wijeysundera HC. Economic evaluation of percutaneous left atrial appendage occlusion, dabigatran, and warfarin for stroke prevention in patients with nonvalvular atrial fibrillation. Circulation. 2013;127:2414-23. 